\title{
Zonificación del conflicto de uso de la tierra en las áreas de protección de la red de drenajes de la cuenca del río Páez, Cartago, Costa Rica.
}

\author{
Zoning of the land use conflict in the protection areas of the \\ drain network of Páez river basin, Cartago, Costa Rica.
}

\author{
Kevin Alfaro-Jiménez ${ }^{1}$ \\ Universidad Nacional, Costa Rica
}

\begin{abstract}
Resumen
El estudio presenta una zonificación de los conflictos de uso de la tierra en las áreas de protección (AP) de los drenajes de la cuenca del río Páez. Dicha zonificación se delimitó y cuantificó mediante procesos de análisis espacial, con base en las curvas de nivel (1:10.000) y la digitalización de ortofotos. Resultando un $59 \%$ del área total de las AP (7,397 km2) bajo algún conflicto de uso. La zonificación del área con conflictos de uso $(4,374 \mathrm{~km} 2)$ se distribuyó: un $4 \%$ en la categoría I (cultivo permanente), un $81 \%$ en la categoría II (agropecuario y cultivos) y por último la categoría III un $16 \%$ (viviendas, infraestructuras, otros). El conflicto generado por los cultivos y en menor grado por el uso agropecuario predomina en la degradación de las funciones de las AP de la cuenca. Apoyando lo anterior, el índice de conflictividad de uso de la tierra (GC) propuesto por Danza y Sanabria (2008) resultó en -0.13, evidenciando una alta afectación en las AP por uso inadecuado de la tierra. Las subcuencas 3, 4, 5, 6, 14 y 20 indican una mayor conflictividad, por lo tanto, las medidas de mitigación deben ser prioritarias en estas áreas espaciales.
\end{abstract}

Palabras clave: zonificación, conflictos de uso de la tierra, cuenca río Páez.

1 Investigador, Laboratorio de Hidrogeología y Manejo de Recursos Hídricos, Escuela de Ciencias Ambientales, Universidad Nacional, Costa Rica. Correo electrónico: kevin15aj@gmail.com

Este artículo corresponde a la ponencia presentada en el I Congreso Centroamericano de Ciencias de la Tierra y el Mar, realizado en San José, Costa Rica, del 13 al 16 de noviembre de 2017. 


\begin{abstract}
This study presents a zoning of land use conflicts in protection areas (AP) of drainages of the Páez river basin. The zoning was delimited and quantified through spatial analysis processes, based on the level curves (1: 10000$)$ and the digitization of orthophotos. Resulting $59 \%$ of the total of AP $\left(7,397 \mathrm{~km}^{2}\right)$ which have a land use conflict. The zoning area with land use conflicts $\left(4,374 \mathrm{~km}^{2}\right)$ was distributed: an $4 \%$ in category I (permanent crop), an $81 \%$ in category II (agricultural and crops) and finally an $16 \%$ in category III (housing, infrastructure and others). The conflict generated by crops and smaller scale by the agricultural use predominate in the degradation of the AP functions at the basin. Confirming the anterior information, the index of land use conflicts (GC) proposed by Danza and Sanabria (2008) resulted in -0.13 , evidencing a high affectation in the AP due to inadequate land use. The sub-basins 3, 4, 5, 6, 14 y 20 indicates a major conflict, therefore, mitigation measures should be a priority in this spatial area.
\end{abstract}

Keywords: zoning, land use conflict, Paéz river basin, watershed.

\title{
Introducción
}

El anárquico expansionismo poblacional ha ocupado los espacios vitales de los ciclos biogeoquímicos (Abhas, Bloch \& Lamond 2012; Walsh et al., 2005; González 1996), especialmente el hidrológico. Los conflictos de uso de la tierra se dan por la discrepancia entre el uso que debería tener la tierra por su oferta ambiental (capacidad de uso), y aquel al que está expuesto por las actividades humanas o uso actual (IGAC y Corpoica, 2002). Estas situaciones degradan los ecosistemas y causan impactos ambientales negativos, acentuándose en las cercanías a las corrientes hídricas, al incrementar el riesgo de que los contaminantes lleguen al cuerpo de agua (Daza \& Sanabria, 2008). Además, estos conflictos ponen en grave peligro la calidad del recurso suelo (IGAC 2007), al concurrir en situaciones en las que, una avanzada erosión, pueda dificultar las acciones de reforestación y recuperación ambiental del bosque ribereño, al reducirse la fertilidad y la capacidad de almacenamiento de agua del suelo (González 1996).

La ley Forestal 7575 dispone en su artículo 33 la creación de un instrumento llamado áreas de protección (AP), que cumple una doble función: una de protección del recurso hídrico y otra como mecanismo de defensa contra amenazas naturales. Estas áreas deben estar cubiertas por la vegetación original o bosque ribereño, para atenuar los efectos erosivos y lixiviantes de la precipitación sobre el suelo, regular el flujo hídrico y reducir los procesos de sedimentación en los cursos de agua (Costa et al. 1996; Apan et al, 2002; Tabacchi et al., 1990), además, de permitir sus funciones de captación y remoción de contaminantes, almacenamiento de aguas de 
inundación, regulación de la temperatura del agua, y provisión de hábitat, recreación y educación (Wender 1999).

El artículo presenta la zonificación de los conflictos de uso de la tierra presentes en las AP de la red de drenaje de la cuenca del río Páez, Cartago, a partir del cual se podrán identificar zonas prioritarias de intervención (Redal et al. 2005), para mejorar la efectividad de los esfuerzos de rehabilitación de áreas. Este está dentro del marco del proyecto 0138-16 denominado "Caracterización biofisica, morfométrica e hidrológica para proponer acciones de manejo de recursos hídricos en la subcuenca del río Páez, Cartago" del Laboratorio de Hidrogeología y Manejo de Recursos Hídricos, de la Escuela de Ciencias Ambientales, y constituye un resultado parcial en investigación técnica al mismo.

\section{Área de Estudio}

El área de estudio corresponde a la subcuenca del río Páez, ubicada en la zona central de la hoja cartográfica nacional Istarú (1:50 000), desde las faldas del volcán Irazú, atravesando la comunidad de Cot y Paraíso de Cartago, hasta llegar al Valle de Ujarrás, desembocando sus aguas a la cuenca alta del río Reventazón. Entre las coordenadas planas 515682 y 519780 m este y 1102192 y 1087436 m norte del sistema de Proyección Transversal de Mercator para Costa Rica (CRTM). Abarcando un área aproximada de $28,34 \mathrm{~km}^{2}$, dedicada principalmente, a la agricultura de hortalizas y pastizales (Tencio 2013; Ledezma, 2009a).

Esta cuenca abarca territorios administrativos tanto del cantón de Oreamuno como de Paraíso de Cartago (Figura 1). El primero cubre las tierras altas de la cuenca, a las faldas del Volcán Irazú, su actividad económica principal es la agrícola de hortalizas: papas, cebollas, zanahorias, lechugas y pastizales (Tencio, 2013 y Ledezma, 2009a). El segundo cubre las tierras más bajas de la cuenca, en general, en los terrenos del sector sur de este cantón se da la producción cafetalera y el aprovechamiento de los abundantes recursos hídricos de la zona; en el sector norte, con la incorporación de los proyectos de parcelación, desarrollados por el Instituto de Desarrollo Agrícola, se da un crecimiento en el aprovechamiento de estas tierras para agricultura tradicional de legumbres y hortalizas (Ledezma, 2009b). 
Figura 1. Ubicación geográfica y división territorial política intrínseca en

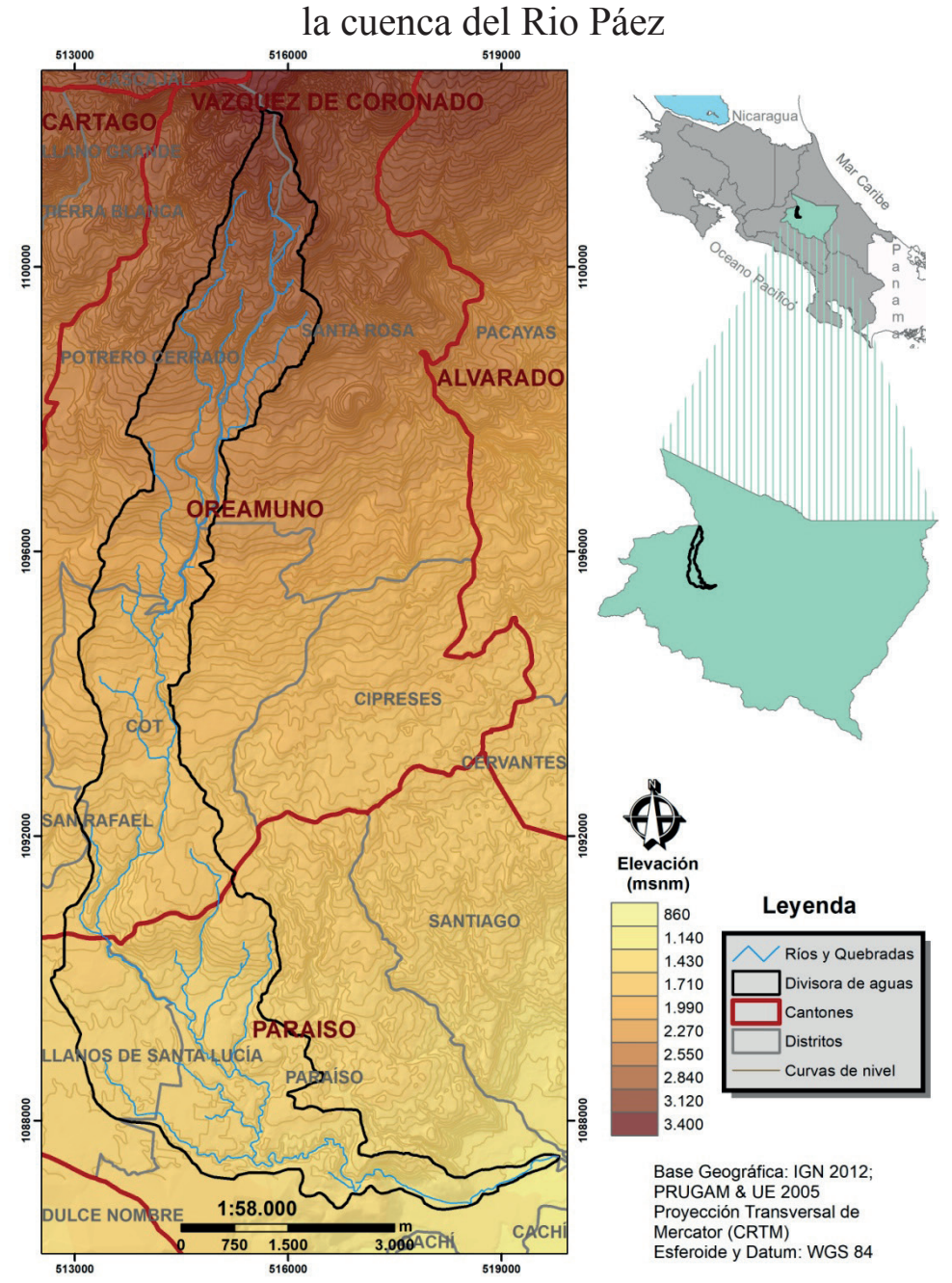

\section{Metodología}

\section{Red de drenaje y divisora de la cuenca}

La cuenca hidrográfica es el espacio de terreno limitado por las partes más altas de las montañas, laderas y colinas, en él se desarrolla un sistema de drenajes superficiales que concentran sus aguas en un río principal, que a su vez se integra a otro río más grande, al mar o lago, este espacio 
se puede delimitar en una carta altimétrica siguiendo las curvas de nivel (Faustino \& Jiménez 2000; Jiménez 2001). Mediante las curvas de nivel digitalizadas previamente de las hojas cartográficas escala 1:10 000 del PRUGAM (PRUGAM \& UE 2005), se creó un vector lineal para la red de drenajes y uno poligonal para la divisoria de aguas.

\section{Uso Actual de la Tierra}

La determinación del uso actual de la tierra se realizó desde la fotointerpretación de imágenes satelitales (Bing y Google EARTH), digitalizando y georreferenciando vectores poligonales de los usos de la tierra, clasificados en bosque, urbano, agropecuario/cultivo y cultivo permanente, vectores que fueron corroborados en campo, a lo largo y ancho de la subcuenca (Figura 2).

Figura 2. Puntos de verificación del uso de la tierra, cuenca Río Paéz

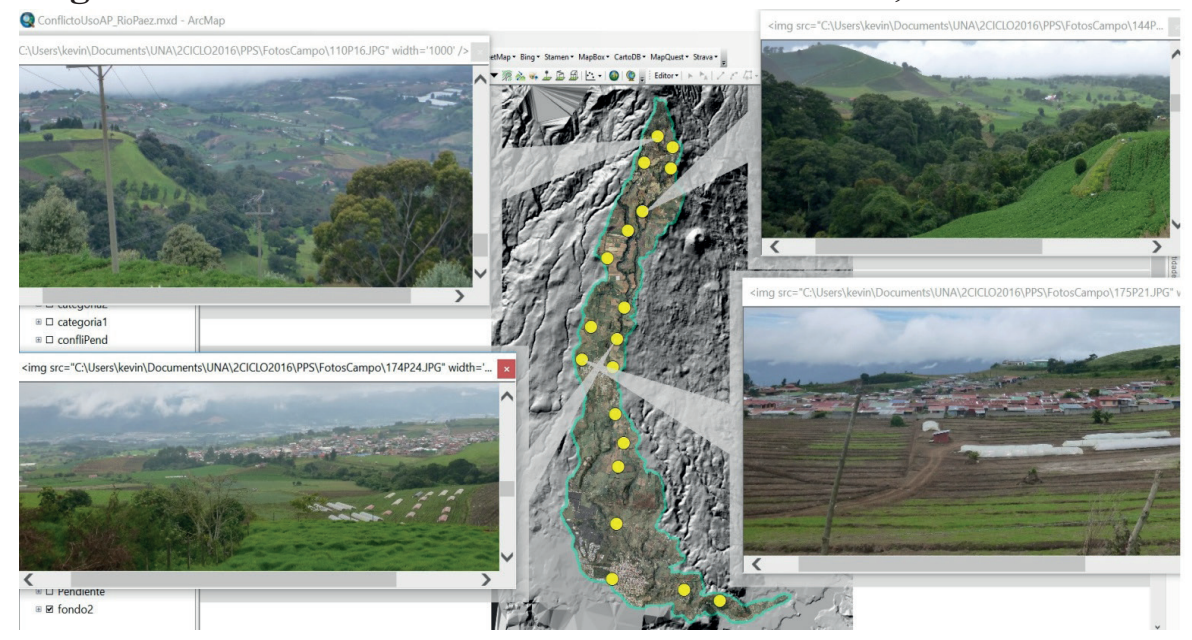

\section{Áreas de Protección (AP)}

Las AP se determinaron según lo dispuesto en la Ley Forestal $\left(\mathrm{N}^{\mathrm{o}}\right.$ 7575), en su artículo 33 referente a ríos y quebradas (Cuadro 1). 
Cuadro 1. Consideraciones para definir las Áreas de Protección (AP)

\begin{tabular}{|c|c|c|}
\hline $\begin{array}{l}\text { Área Protegida } \\
\text { (AP) }\end{array}$ & Pendiente & Zona de Amortiguamiento (buffer) \\
\hline \multirow{3}{*}{$\begin{array}{l}\text { AP de ríos y } \\
\text { quebradas }\end{array}$} & Superior a $40 \%$ & - $50 \mathrm{~m}$ horizontales ambos lados de borde. \\
\hline & \multirow{2}{*}{ Inferiores a $40 \%$} & $\begin{array}{l}-15 \mathrm{~m} \text { horizontales ambos lados de borde en } \\
\text { zonas rurales. }\end{array}$ \\
\hline & & $\begin{array}{l}\text { - } 10 \mathrm{~m} \text { horizontales ambos lados de borde en } \\
\text { zonas urbanas. }\end{array}$ \\
\hline
\end{tabular}

Fuente: Elaboración propia con datos de la Ley Forestal 7575 de Costa Rica.

Primeramente, se creó un mapa de pendientes en la cuenca (en dos rangos $\geq 40 \%$ y $<40 \%$ ), mediante un modelado digital de las elevaciones (MED), basado en las curvas de nivel (1:10 000). Posteriormente, se establecieron las zonas de amortiguamiento con herramientas de geoprocesamiento, donde a partir del vector lineal (drenajes) se crea un vector poligonal (zona de amortiguamiento) que abarque una distancia de 10, 15 y $50 \mathrm{~m}$ a ambos lados del drenaje. Siguiendo con la conversión de las capas obtenidas (uso actual de la tierra, pendientes y zonas de amortiguamiento) a formato raster, permitiendo el empleo de algebra de mapas, que con sus respectiva sentencias de operadores booleanos $(\mathrm{Y} / \mathrm{O})$ y operadores relacionales $(<,<=,>,>=,==, !=)$ se procedió a generar las respectivas AP para cada sección de la red de drenajes (Cuadro 2 y Figura 3).

Cuadro 2. Sentencias álgebra de mapas para generar las

AP de la red de drenajes

\begin{tabular}{|c|c|}
\hline & Insumos de entrada \\
\hline Zonas amortiguamiento $=$ & $\begin{array}{l}10 \mathrm{~m}=\text { Buffer 10.grid } \\
15 \mathrm{~m}=\text { Buffer 15.grid } \\
50 \mathrm{~m}=\text { Buffer 50.grid }\end{array}$ \\
\hline Uso actual de la tierra $=$ & UsoActual.grid \\
\hline Pendientes $\geq 40 \%$ y $<40 \%=$ & Pend40.grid \\
\hline \multicolumn{2}{|c|}{ Sentencia de operadores en álgebra de mapas } \\
\hline Producto & Sentencia \\
\hline AP10.grid $=$ & $(($ "UsoActual" = = urbano $\&$ ("Buffer 10" = = 1)) \\
\hline AP15.grid $=$ & $\begin{array}{l}(\text { ("UsoActual" }=\text { cultivo permanente) } \mid \text { ("UsoAc- } \\
\text { tual" }==\text { agrope cult }) \&(" B u f f e r 15 "==1))\end{array}$ \\
\hline AP50.grid $=$ & $((" P$ end $40 "==1) \&(" B u f f e r 50 "==1))$ \\
\hline
\end{tabular}


Zonificación del conflicto de uso de la tierra en las áreas de protección de la red de drenajes de la cuenca del río Páez, Cartago, Costa Rica.

Figura 3. Metodología para generar las AP de ríos y quebradas

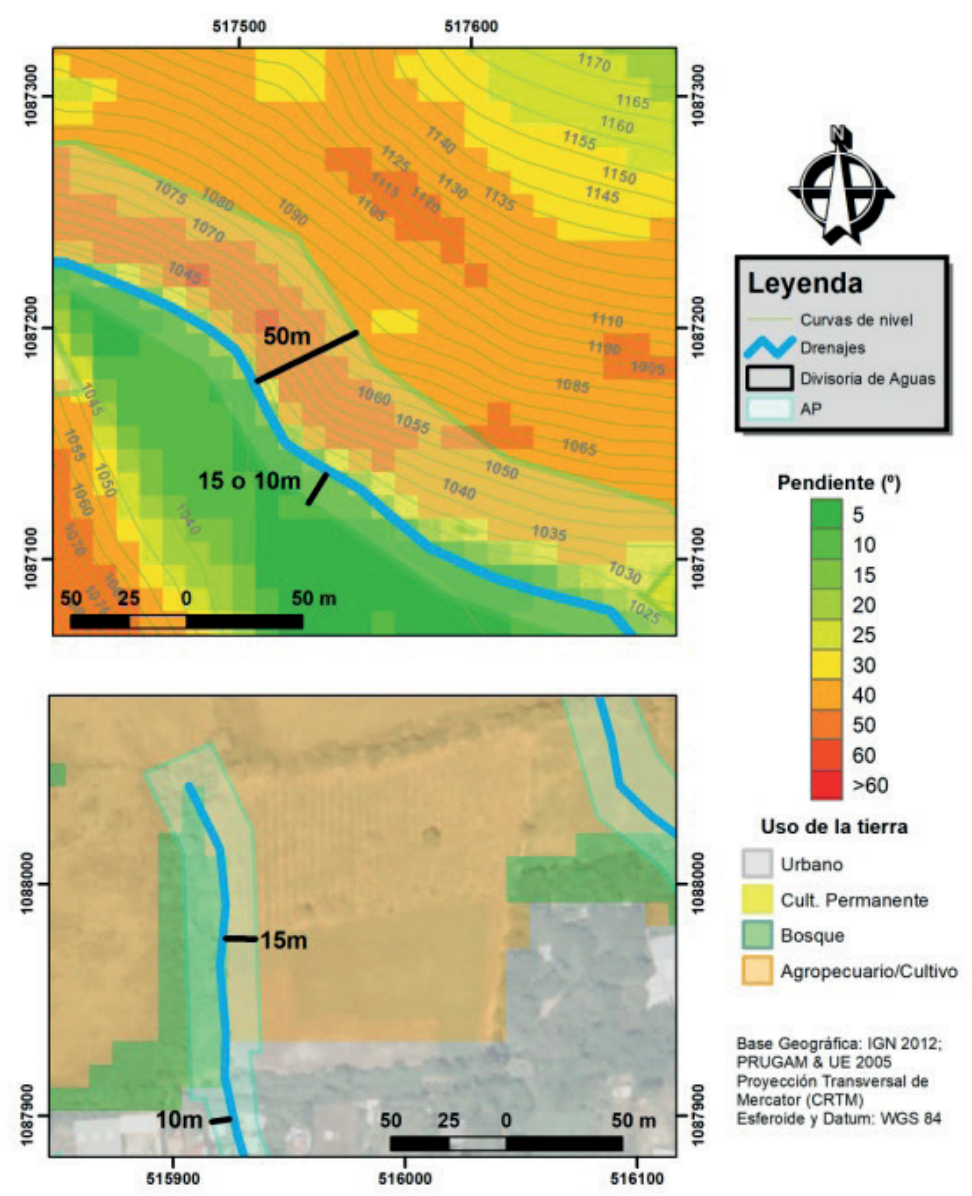

\section{Zonificación de conflicto de uso de la tierra}

La cartografía de los conflictos de uso de la tierra en las AP se realizó mediante álgebra de mapa, usando de entrada el raster AP y el de uso actual de la tierra, cartografiándose como conflicto toda área dentro de las AP que no correspondan a bosque. Posterior y con las mismas herramientas usadas en la cartografía de los conflictos de uso se zonificaron los conflictos de uso de la tierra en las AP, de acuerdo con las categorías establecidas: I) cultivos permanentes y pastos en reposo; II) áreas con usos agropecuarios y cultivos anuales; III) presencia de viviendas, industrias y cualquier otro tipo de infraestructura (Cuadro 3). Con la premisa que a 
mayor categoría así mayor será la prioridad de intervención, considerando que una alta conflictividad en el uso de la tierra está asociada con una alta degradación ambiental (IGAC \& Corpoica 2002).

Cuadro 3. Sentencias en algebra de mapas para generar la zonificación del conflicto de uso de la tierra

\begin{tabular}{|c|c|}
\hline \multicolumn{2}{|r|}{ Insumos de entrada } \\
\hline AP de la red de drenajes $=$ & AP.grid \\
\hline Uso actual de la tierra $=$ & UsoActual.grid \\
\hline Conflicto de uso de la tierra $=$ & Conflictos grid \\
\hline \multicolumn{2}{|c|}{$\begin{array}{r}\text { Sentencia de operadores en álgebra de mapas } \\
\end{array}$} \\
\hline Producto & $\begin{array}{r}\text { Sentencia } \\
\end{array}$ \\
\hline Conflictos.grid $=$ & $\begin{array}{l}((" \text { AP" }==1) \&(" \text { UsoActual } "==\text { urbano }) \\
\mid(" \text { UsoActual } "==\text { cultivo_permanente }) \mid \\
(" \text { UsoActual" = = agrope_cult })\end{array}$ \\
\hline Cat_I.grid $=$ & $\begin{array}{l}((" \text { Conflictos } "==1) \&(" \text { UsoActual } "== \\
\text { cultivo_permanente })\end{array}$ \\
\hline Cat_II.grid $=$ & $\begin{array}{l}((" \text { "Conflictos" }==1) \&(\text { "UsoActual" }== \\
\text { agrope_cult })\end{array}$ \\
\hline Cat_III.grid $=$ & $\begin{array}{l}((\text { "Conflictos" }==1) \&(" \text { UsoActual } "== \\
\text { urbano })\end{array}$ \\
\hline
\end{tabular}

Para cuantificar la conflictividad presente en las AP se aplicó el indicador Grado de Conflicto de Uso de la Tierra (GC), propuesto por Danza y Sanabria (2008), cuya ecuación original (Ecuación 1) usa como variables las áreas de los conflictos bajo, medio, alto y crecimiento urbano; variables que en el estudio están dadas por: categoría I (bajo), categoría II (medio) y categoría III (alto y crecimiento urbano).

$$
G C=\frac{(E+B)-(A+M)}{A v}
$$

Ecuación 1

Donde: E: es el área sin conflicto, B: área con conflicto bajo (categoría I), M: área con conflicto medio (categoría II), A: área conflicto alto (categoría III, incluyéndose en este la variable crecimiento urbano) y Av: área total de las AP. 
Kevin Alfaro-Jiménez

Zonificación del conflicto de uso de la tierra en las áreas de protección de la red de drenajes de la cuenca del río Páez, Cartago, Costa Rica.

Los valores resultantes del indicador pueden variar de -1 a 1 , valores cercanos a -1 indica un mayor grado de conflictividad de uso de la tierra, mientras que valores cercanos a 1 indica un menor grado de conflictividad. Interpretándose que 1, la totalidad de las AP se encuentran con cobertura arbórea (están en equilibrio), igual a 0 , la categoría I y las áreas sin conflicto son iguales a las categorías más conflictivas (II y III). Además, siguiendo las la divisoria de agua, a partir de loa drenajes que desembocan sus aguas directamente al cauce principal de la cuenca, se delimitaron las subcuencas de la cuenca del rio Paéz, a las cuales se les cuantificó el GC individualmente (Figura 4).

Figura 4. Diagrama representativo de los productos obtenidos

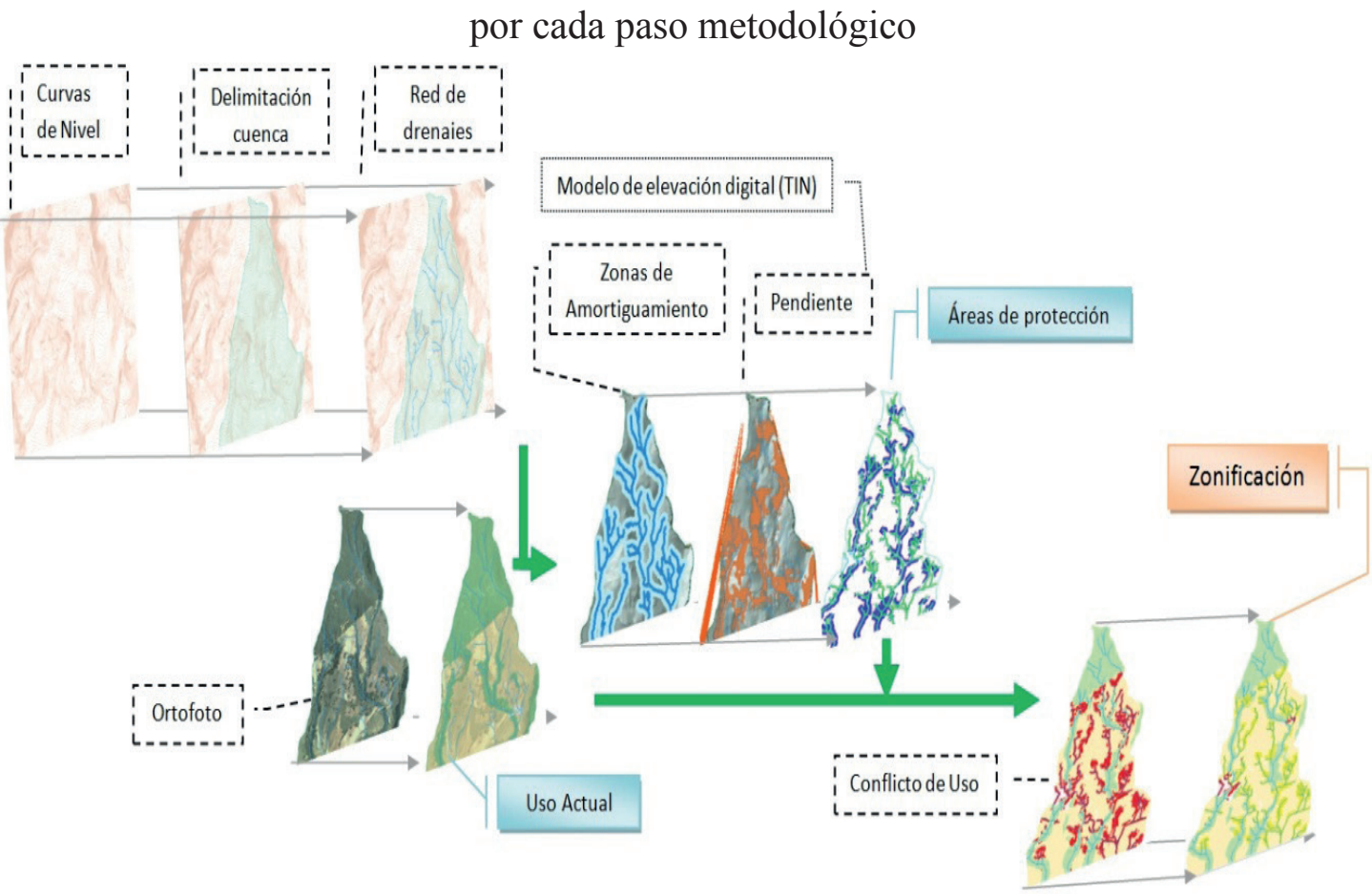




\section{Resultados}

El análisis espacial y recorrido de campo generó en primera instancia el mapa de uso actual de la tierra y AP (Figura 5). Las figuras geográficas cartografiadas cuantificaron una longitud aproximada de $172,44 \mathrm{~km}$ de la red drenajes, una zona de 7,39 km2 para AP, un uso de la tierra dominado por actividades agropecuario/cultivos, representando un $68 \%$ del área de la cuenca (correspondiendo con lo visualizado en campo), mientras que el uso urbano, cultivo permanente y bosque representan un $14 \%, 3 \%$ y $15 \%$ de la cuenca, respectivamente (Cuadro 4).

Cuadro 4. Área absoluta y porcentual por uso actual de la tierra

\begin{tabular}{lrr}
\hline \multirow{2}{*}{ Uso Actual } & \multicolumn{2}{c}{ Área } \\
\cline { 2 - 3 } & Km2 & \multicolumn{1}{c}{$\%$} \\
\hline Urbano & 3,97 & $14 \%$ \\
\hline Cultivo Permanente & 0,71 & $3 \%$ \\
\hline Agropecuario/cultivo & 19,36 & $68 \%$ \\
\hline Bosque & 4,35 & $15 \%$ \\
\hline Total & $\mathbf{2 8 , 3 9}$ & $\mathbf{1 0 0 \%}$ \\
\hline
\end{tabular}

En segunda instancia se generó el mapa de zonificación de conflictos de uso de la tierra en las AP (Figura 6), resultando un $59 \%(4,374 \mathrm{~km} 2)$ de las AP bajo algún conflicto de uso, área de la cual un 4\% presenta conflictos categoría I (cultivo permanente), el $81 \%$ en categoría II (agropecuario y cultivos) y por último un $16 \%$ categoría III (viviendas, infraestructuras, otros; Figura 6). El cálculo del índice GC de la cuenca en general da como resultado $-0,13$, señalando que la cuenca presenta alta conflictividad. 
Kevin Alfaro-Jiménez

Zonificación del conflicto de uso de la tierra en las áreas de protección de la red de drenajes de la cuenca del río Páez, Cartago, Costa Rica.

Figura 5. Uso de la tierra y AP de los drenajes, cuenca del río Páez

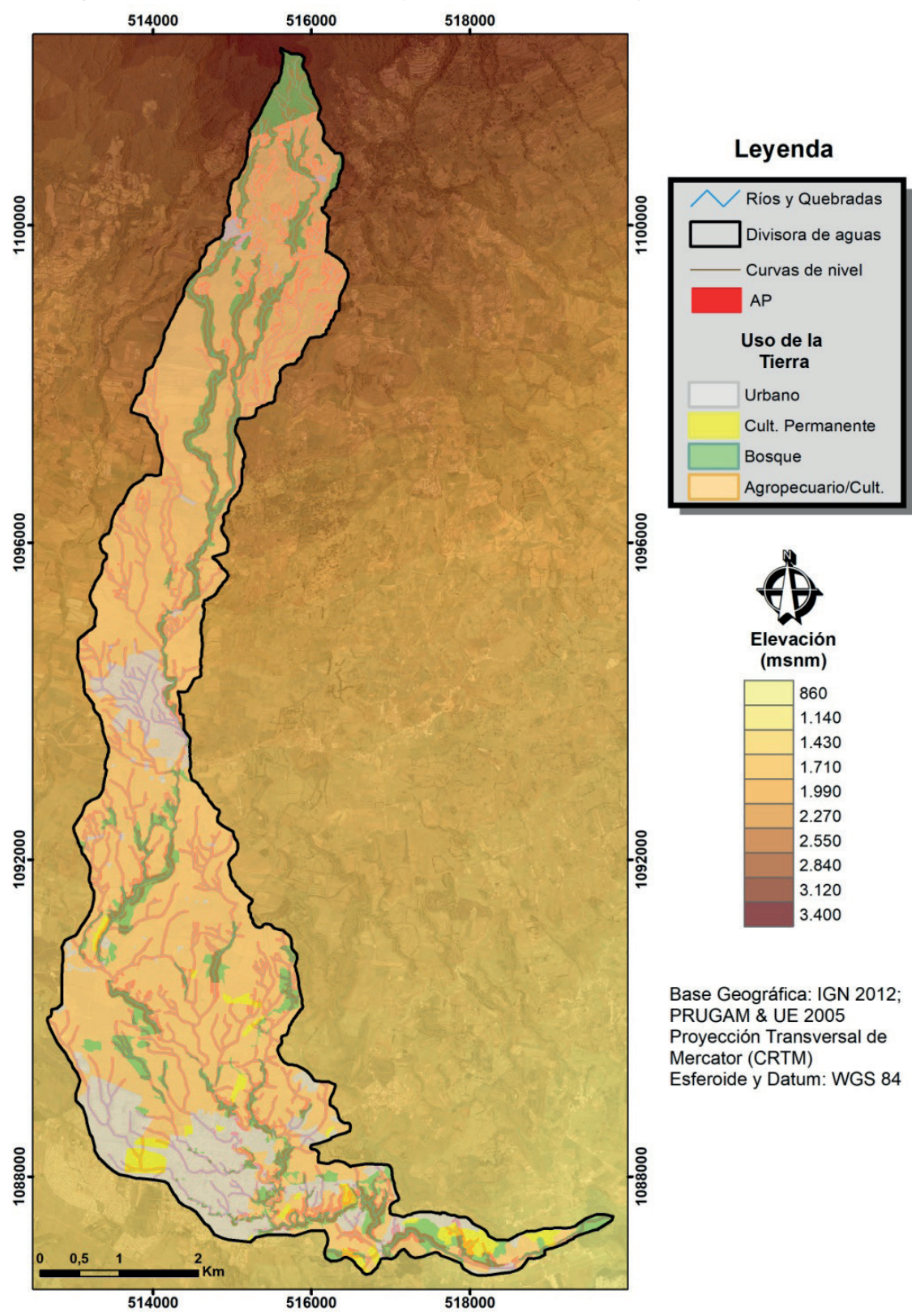


Figura 6. Área de protección en conflicto y distribución porcentual de la zonificación de conflictos

\begin{tabular}{ccc}
\hline \multirow{2}{*}{ Conflicto } & \multicolumn{2}{c}{ Área } \\
\cline { 2 - 3 } & $\mathbf{K m 2}$ & $\mathbf{\%}$ \\
\hline Ausente & 3,023 & $41 \%$ \\
\hline Presente & 4,374 & $59 \%$ \\
\hline Total & $\mathbf{7 , 3 9 7}$ & $\mathbf{4 1 \%}$ \\
\hline
\end{tabular}

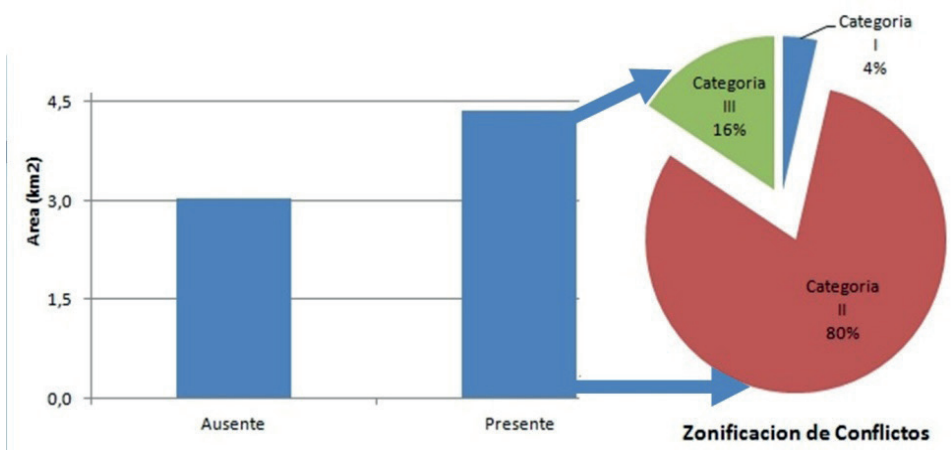

Además de la zonificación de los conflictos de uso, en las AP de la cuenca en general, se obtuvieron por cada una de las 22 subcuencas cartografiadas resultados detallados del área de cada categoría de zonificación de conflicto, longitud total de los drenajes e índice de GC, generando un mapa que permite focalizar la atención en subáreas de gestión (subcuencas con GC críticos) de la unidad de gestión, tal cual es la cuenca hidrográfica, lo cual permite trabajar secciones pequeñas de manera independiente y dentro de ellas trabajar en las AP con una categoría de zonificación mayor, al considerar estas como las áreas más críticas (Figura 7). Del análisis detallado de las subcuencas se rectifica el dominio de la categoría II en las AP, con excepción de las subcuencas 1 y 2 (la subcuenca 0 corresponde al cauce principal, por lo que no se toma en consideración, aunque es importante indicar que las AP de estos trayectos están dominados por una cubierta arbórea), que presentan una mayor cobertura de vegetación arbórea, por lo tanto, una mayor área sin conflicto de uso (Figura 8). 
Kevin Alfaro-Jiménez

Zonificación del conflicto de uso de la tierra en las áreas de protección de la red de drenajes de la cuenca del río Páez, Cartago, Costa Rica.

Figura 7. Distribución del uso de la tierra en las AP e índice GC por subcuenca

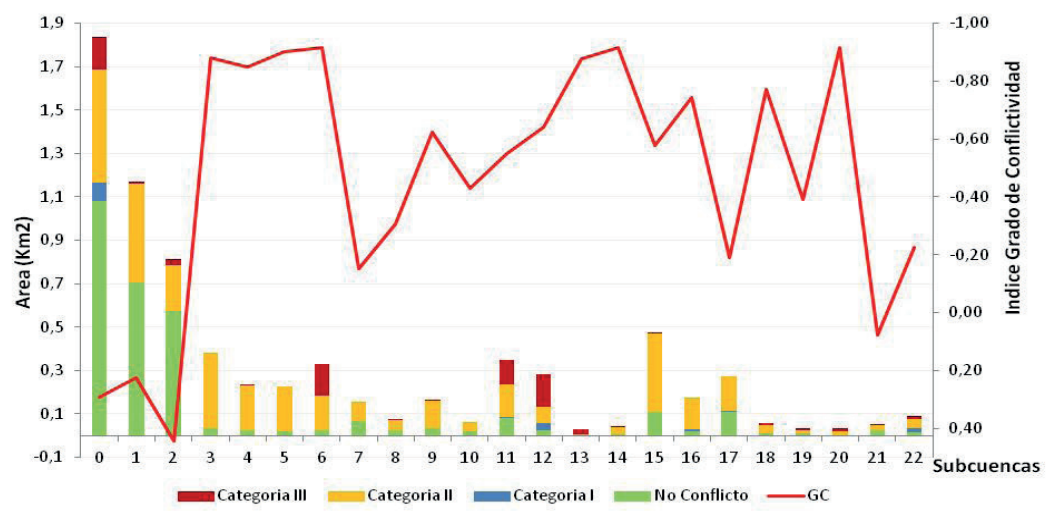

Figura 8. Índice de GC y zonificación del conflicto de uso en las AP de cada subcuenca

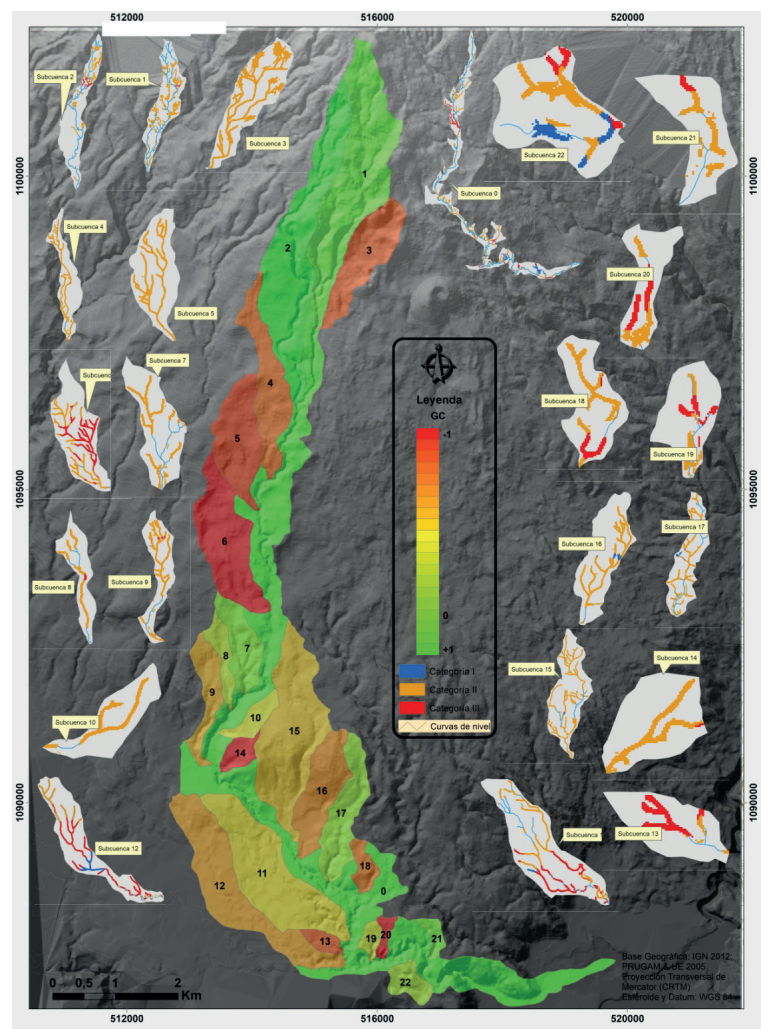




\section{Discusión}

En los resultados obtenidos del presente estudio el conflicto de uso imperante es la categoría II, que corresponde a uso agropecuario/cultivo, por lo tanto, se infiere que el principal causante de la perdida de ecosistemas riparios es dicha actividad (Esquivel y Valerio 2013); esto provoca la fragmentación del ecosistema, al dejar pequeños fragmentos de bosque que dificultan la conectividad ecológica y disminuyen la capacidad de brindar servicios ecosistémicos (Tabacchi et al. 1990), consecuentemente, se da la modificación de la capacidad de retención hídrica de la cuenca, en la torrencialidad, la velocidad de respuesta, el tiempo de concentración, y el volumen de los caudales (Esquivel \& Valerio 2013; Ferrando 2006; Morera, Pinto \& Romero 2007; Sanchun et al. 2016), sin omitir que las concentraciones urbanas en las orillas de los ríos (14\% de la cuenca) representa otra causa importante de la degradación de las AP, principalmente por afectar la calidad de los cuerpos de agua (Buzolich et al. 2007).

El $59 \%$ de las AP de la red de drenaje de la cuenca presenta algún conflicto de uso de la tierra, lo cual evidencia la pérdida del ecosistema ripario y consecuentemente un alto grado de conflictividad $(-0,13)$, en expectativa, hay un mayor área cubierta por conflictos críticos, que zonas con conflictos menos críticos o sin conflicto. Esta situación inhibe la susceptibilidad de la cuenca a problemas de erosión, lixiviación de los suelos e irregularidad del flujo hídrico, además, aumenta los procesos de sedimentación de los cursos de agua (Costa et al. 1996), dificulta las acciones de reforestación y recuperación ambiental del bosque ribereño, al reducirse la fertilidad y la capacidad de almacenamiento de agua del suelo (González 1996), y con ello, disminuye la capacidad amortiguadora de estos bosques a eventuales crecidas e inundaciones, que se tornan más frecuentes ante las precipitaciones (Wender 1999).

Las cuencas hidrográficas al ser sistemas naturales y dinámicos, que funcionan como unidades de gestión, en donde lo que se haga en una zona de esta repercutirá en determinado tiempo en el resto de ella (Ferrando, 2006), es la razón por la que la gestión integral de cuencas aparece como una herramienta que puede contribuir a la mitigación de los procesos de inundación (Ureña 2002), uno de los enfoques básicos es que los procesos que ocurren al interior de las cuencas, sean naturales o potenciados por acción humana, deben ser controlados desde su inicio (es decir, desde el 
nacimiento de los cursos de agua), ya que resulta más difícil, que medidas aplicadas en las secciones medias e inferiores de los sistemas de drenaje tengan éxito si la causa del evento se viene potenciando desde la sección superior de las cuencas (Ferrando 2006). Por lo tanto, en consideración de lo anterior es prioritaria la intervención de las subcuencas $3,4,5,6,14$ y 20 (Figura 7), en dicho orden.

Mantener o aumentar la capacidad de retención hídrica en las secciones superiores de las cuencas, mediante la protección y recuperación de la cobertura vegetal nativa u otra equivalente en las AP, reducirá las capacidades erosivas y de transporte de sedimentos de los flujos hídricos, también mejorará la efectividad de las medidas de mitigación ante eventos de crecidas y semejantes a esta naturaleza (Delgado \& Villegas 2013; Ferrando, 2006). Cannata (1996) destaca una postura interesante para mitigar los problemas de inundaciones que se apoyan en lo anterior y que quizá sea más difícil de implementar, pero ciertamente más eficaz, deseable y ventajoso, consiste en favorecer un nuevo equilibrio dinámico, mediante el ordenamiento y protección con normas de uso de la tierra, al priorizar obras de restauración hidrológico-forestal, y limitar las grandes obras de regulación y restauración artificial. Esta postura fomenta los bosques de ribera como retardantes de la llegada de la escorrentía al cauce, en consecuencia, se reduce el volumen de las corrientes y se favorece la infiltración de aguas superficiales, además, mediante la implementación de pavimentos porosos o áreas especiales de infiltración en las áreas urbanas es posible incrementar los anteriores efectos (Ureña 2002; Kauffman \& Brant 2000), este aspecto es muy importante realizarlo, no solamente con el espacio estrictamente urbano, sino con los espacios periurbanos y/o rurales anteriores y pertenecientes a la misma vertiente.

Las AP constituyen una figura jurídica importante en la protección del recurso hídrico, al presentar una doble función, 1) protección y conservación, y 2) como zonas de amortiguamiento ante eventos naturales (Valdés 2010; Delgado \& Villegas 2013), sin embargo, es un área que se ha dejado de lado por la necesidad de un "desarrollo" (que amerita un enfoque al aspecto económico, no así un desarrollo sostenible), que requiere la creciente población, al menospreciar la importancia de las mismas para el ecosistema y al ignorar la importancia que posee estas como figura jurídica, volviéndose una norma más de la legislación. 
En consecuencia, es recomendable incrementar el uso de la vegetación como técnica de estabilización de riberas, la creación de sobreelevaciones contra las inundaciones y de mejora de la calidad ambiental (Ureña 2002). La incorporación de sistemas agroforestales que logren un máximo beneficio al propietario sin causar deterioro en los recursos naturales apuntan a ser una alternativa al desarrollo sostenible. En miras de lo anterior el Gobierno de Costa Rica inició en 2013 un diálogo con el Banco Mundial sobre la posibilidad de colaborar en la preparación de una visión y estrategia de Crecimiento Verde e Inclusivo (CVI) para los paisajes rurales productivos del país, que permitan la diversificación de la productividad en el espacio rural, así como la disminución de la vulnerabilidad económica y ambiental (Vignola, Otarola, Majano, \& Kilian 2014).

\section{Conclusiones}

La zonificación del conflicto de uso de la tierra es una herramienta que permite definir áreas prioritarias de intervención, a priori si se secciona la cuenca en unidades menores de gestión (subcuencas). La afectación de los conflictos de uso de la tierra en una cuenca puede ser reflejada con el índice de grado de conflictividad, el cual en la cuenca en estudio sugirió una alta degradación causada por la actividad agropecuaria/cultivo, en primera instancia, y en segunda instancia por el uso urbano, pudiéndose ver afectados directamente los cursos de agua en calidad y cantidad. Pese a que las áreas en categoría III suponen una menor degradación ambiental, no debe admitirse su uso actual, debido a que todo cambio de uso que implique la eliminación de cobertura natural de los corredores hídricos afecta la calidad y cantidad del recurso.

Cualquier medida o metodología que se tome en cuenta debe considerar el sistema completo (desde el origen hasta el desemboque), promoviendo el equilibrio dinámico de las corrientes mediante el incremento de la vegetación original como técnica de estabilización de riberas e implementación de obras difusas y limitadas de regulación y restauración artificial.

\section{Referencias}

Abhas, K., Bloch, R. \& Lamond, J. (2012). Ciudades e Inundaciones: Guía para la Gestión Integrada del Riesgo (Resumen para hacedores de 
políticas). Washington: International Bank for Reconstruction and Development /International Development Association.

Apan, A., Raine, S. \& Paterson, M. (2002). Mapping and analysis of changes in the riparian landscape structure of the Lockyer Valley catchment, Queensland, Australia. Landscape and Urban Planning , 59 (1), 43-57.

Buzolich, G. (2007). Capacidad potencial de las franjas riberenas del rio Bermudez para reducir la erosion. Recursos Naturales y Ambiente, 51-52, 175-183. Turrialba, CR.: CATIE.

Cannata, P. (1996). Ríos, cuencas hidrográficas y planificación territorial. En J. Martin, \& J. Montalvo, Agua y paisaje: naturaleza, cultura y desarrollo. 175-198. España: Multimedia Ambiental.

Costa, T., Souza, M., \& Brites, R. (1996). La delimitacion y caracterizacion de areas de preservacion permanente, a traves de un sistema de informacion geografica. VIII Simposio Brasileno de Sensoramiento Remoto. Salvador, Brasil

Daza, O. \& Sanabria, R. (2008). Identificación de conflictos de uso de suelo en rondas hídricas: herramienta para manejo ambiental. Caso de estudio municipio de Paipa. Perspectiva Geográfica, 13, 13-26.

Delgado, V. \& Villegas, M. (2013). Evaluacion territorial sobre la disponibilidad de recurso hidrico y recurrencia de eventos extremos secos en la subcuenca del rio Sandoval, Costa Rica. Seminario de graduacion de Licenciatura en Ciencias Geografica, Universidad Nacional de Costa Rica, Heredia.

Esquivel, A. \& Valerio, L. (2013). Propuesta de restauracion forestal de las areas de proteccion de los principales afluentes del Corredor Biologico. (Tesis Licenciatura en Restauracion de Ecosistemas Forestales. Universidad Nacional de Costa Rica). Heredia.

Faustino, J. \& Jiménez, F. (2000). Manejo de Cuencas Hidrográficas. Turrialba, CR.: Centro Agronómico Tropical de Investigación y Enseñanza (CATIE), Área de Cuencas y Sistemas Agroforestales.

Ferrando, F. (2006). Sobre inundaciones y anegamientos: Flood Disasters. Revista de Urbanismo (12), 25-42.

González, M. (1996). Impacto de la agricultura en los sistemas fluviales. Técnicas de restauración para la conservación del suelo y del agua. Agricultura y sociedad, 78, 211-236. 
Instituto Geográfico Agustin Codazzi (IGAC). (2007). Subdireccion de Agricultura: Estudio semidetallado de las coberturas terrestres. Bogota.: Imprenta Nacional de Colombia.

Instituto Geográfico Agustin Codazzi (IGAC) \& Corpoica. (2002). Zonificación de los conflictos de uso de las tierras en Colombia. Bogotá, D.C. Jiménez, F. (2001). Conceptos, estrategias y diagnósticos en el majeo de la cuencas hidrográficas. Turrialba, CR.: Centro Agronomico Tropical de Investigacion y Ensenanza (CATIE).

Kauffman, G. \& Brant, T. (2000). The Role of Impervious Cover as a Watershed-Based Zoning Tool to Protect Water Quality in the Christina River Basin of Delaware, Pennsylvania, and Maryland. Water Res. Agency .

Ledezma, A. (2009a) Diagnóstico Inicial de la Situación de los Residuos Sólidos en la Municipalidad de Oreamuno. Cartago, CR.: Instituto Tecnológico de Costa Rica (ITCR). (b) Diagnóstico Inicial de la Situación de los Residuos Sólidos en la Municipalidad de Paraíso. Cartago, CR.: Instituto Tecnológico de Costa Rica (ITCR).

Morera, C., Pinto, J., \& Romero, M. (2007). Paisajes procesos de fragmentación y redes ecológicas aproximación conceptual, (11-47) . Corredores Biológicos: Acercarmiento conceptual y experiencia en América. Imprenta Nacional. San Jose, Costa Rica.

PRUGAM, \& UE. (2005). Cartografía: Cuadrante Sur-Este . San Jose, CR.: Ministerio de Vivienda y Asentamientos Humanos.

Redal, L., Carrasco, I., \& Gordillo, A. (2005). Influencia de los usos del suelo sobre la calidad en la cuenca alta del rio Peñas Blancas, y estudio de alternativas de desarrollo rural más sostenible. Centro Científico Tropical.

Sanchún, A., Botero, R., Morera-Beita, A., Obando, G., \& Ricardo, O. (2016). Restauración funcional del paisaje rural: manual de técnicas. UICN. San Jose, Costa Rica.XIV.

Tabacchi, E., Planty-Tabacchi, A., \& Decamps, O. (1990). Continuity and discontinuity of the riparian vegetation along a fluvial corridor. Landscape Ecology , 1 (5), 9-20.

Tencio, R. (2013). Información General de la Región Central Oriental. San Jose, CR.: Ministerio de Ganadería y Agricultura (MAG). 
Urena, J. (2002). La ordenacion de los espacios fluviales en las ciudades. ( 45-63). En P. De la Cal, \& F. Pellicer, Rios y ciudades: Aportaciones para larecuperacion de los rios y riberas de Zaragoza. Zaragoza: Institucion Fernando el Catolico.

Valdes, M. (2010). Las Areas de Proteccion del articulo 33 de la Ley Forestal: El caso de la quebrada Los Negritos en el sector de Montes de Oca. (Tesis de Licenciatura en Derecho, Facultad de Derecho). Universidad de Costa Rica. San Jose..

Vignola, R., Otarola, M., Majano, A. \& Kilian, B. (2014). Metodologia para la evaluacion del entorno politico, socioeconomico y ambiental para un programa de crecimiento verde e inclusivo: Estudio de caso en paisajes productivos de Costa Rica. San Jose: CATIE, INCAE y Banco Mundial.

Walsh, C., Roy, A., Feminella, J., Conttingham, P., Groffman, P. \& Morgan, R. (2005). The urban stream syndrome: current knowledge and the search for a cure. JN Am Benthol Soc. , 24, 706-223.

Wender, S. (1999). A review of scientific literature of riparian buffers width, extend and vegetation. Institute of Ecology, University of Georgia, Athens, Georgia.. 